Article

\title{
Physicochemical Characteristics, Fatty Acid Profile, Alpha-Tocopherol Content, and Lipid Oxidation of Meat from Ewes Fed Different Levels of Distilled Myrtle Residues
}

\author{
Souha Tibaoui ${ }^{1,2}$, Samir Smeti ${ }^{1}$, Ines Essid ${ }^{2}$, Juan Ramón Bertolín ${ }^{3}$, Margalida Joy ${ }^{3}$ (i) \\ and Naziha Atti ${ }^{1, *}$ \\ 1 Laboratoire de Productions Animales et Fourragères, INRA-Tunisia, University of Carthage, rue Hédi Karray, \\ Ariana 2049, Tunisia; souhatibaoui@gmail.com (S.T.); sam_fsb@live.fr (S.S.) \\ 2 UR-UR PATIO (UR17AGR01), INAT, University of Carthage, 43 Avenue Charles Nicole, Tunis 1082, Tunisia; \\ essidiness@gmail.com \\ 3 Centro de Investigación y Tecnología Agroalimentaria de Aragón (CITA), Instituto Agroalimentario de \\ Aragón-IA2, CITA-Universidad de Zaragoza, Avda. Montañana 930, 50059 Zaragoza, Spain; \\ jrbertolin@cita-aragon.es (J.R.B.); mjoy@cita-aragon.es (M.J.) \\ * Correspondence: naziha.atti@gmail.com
}

Academic Editors: Adam Figiel and Anna Michalska-Ciechanowska

Received: 7 September 2020; Accepted: 25 September 2020; Published: 27 October 2020

check for updates

\begin{abstract}
The aim of this work was to study the sheep meat physicochemical traits as affected by distilled myrtle residues (MR) supplementation. For this, 27 culled ewes were divided into three groups receiving a ration composed by concentrate and hay for the Control group, concentrate and MR as a total substitute to hay for the Myrt-H group, or hay, less concentrate, and MR as a partial substitute to concentrate for the Myrt- $\mathrm{C}$ group. The meat chemical composition, $\mathrm{pH}$, and color parameters were not affected by the MR intake. However, this animal's dietary treatment resulted in higher meat polyphenol and $\alpha$-tocopherol content for both MR groups (9.38 and $8.05 \mathrm{vs.} 3.04 \mu \mathrm{g} \mathrm{g}^{-1}$ DM for Myrt-H, Myrt-C, and Control, respectively). In addition, since day 3 of meat storage, the lipid oxidation was improved by MR intake being lower for both MR groups than the Control ( $0.51 \mathrm{vs.}$ $1.11 \mathrm{mg}$ MDA $/ \mathrm{kg}$ of meat). The total polyunsaturated fatty acid (PUFA) and saturated fatty acid (SFA) were similar among groups. However, the meat of Myrt-H had the highest C18:2n-6 and total PUFAn-6. In conclusion, the MR intake could be useful given it increases the meat content of vitamin $\mathrm{E}$ and improves its oxidative status without negative effects on the FA profile.
\end{abstract}

Keywords: food; sheep meat; color parameters; oxidative status; fatty acids; myrtle residues

\section{Introduction}

As human food, the meat and meat products quality (color, fatty acid (FA) composition, lipid oxidation, etc.) depend on the feed of animals [1-3]. The consumer's tendency of choice is oriented to foods rich in polyunsaturated FA (PUFA), with low saturated FA (SFA) content, since they are associated with increased LDL cholesterol [4]. On the other hand, meat color is the main factor influencing consumers' purchasing choice, while flavor is judged during eating. Lipid oxidation is considered as one of the major deteriorating process of meat color and flavor; it is inevitable and irreversible that this phenomenon affected the meat traits during transformation, storage, and distribution, reducing the shelf life, leading to discoloration and off-flavor [5,6]. Apart from sensory quality deterioration, lipid oxidation causes oxidative reactions in the meat through the degradation of PUFA, which generate residual products, such as malondialdehyde (MDA) and lipid-derived 
volatiles [7]. For this, the use of synthetic antioxidant was widely practiced as an ingredient in animal diet or as an additive in meat products. However, they may be associated to anti-nutritional effects or toxicological consequence, so the use of such substances became rejected by consumers [8]. Smart animal nutrition strategies are now using natural antioxidants in order to satisfy consumer's demands for a healthier product $[9,10]$. Hence, the incorporation of aromatic and medicinal plants or their extract in animal's diet may be considered as an alternative method to inhibit or delay meat oxidation. Given their richness in phenolic compounds, these plants could be a major determinant of the antioxidant potentials of meat [11]. The antioxidant power of plant extracts or essential oils has been reported in various meats such as pork [12] and lamb meat [1,11,13]. The distillation industry of aromatic and medicinal plants generates substantial quantities of phenolic-rich by-products, which could be valuable natural sources of antioxidants. Some of these by-products, such as rosemary and thyme distillate leave, have been the subject of several investigations and have proven to be effective sources of phenolic antioxidants [10,14,15]. Myrtle (Myrtus communis L.) is an aromatic plant shrub distributed throughout the Mediterranean area that is widely used in folk medicinal practices as an antimicrobial and antioxidant. Several authors investigated the use of myrtle essential oil in the poultry diet $[16,17]$. Distilled myrtle residues (MR) are discarded after the extraction of essential oils; they could be an interesting alternative feed for animals given their protein and energy content and their richness in bioactive compounds [18], especially in regions suffering from insufficient feeding resources. On the other hand, culled ewes offered great quantities of meat; however, this meat is usually tough and fibrous in texture [19], it accumulates more branched-chain fatty acids [20], and it is more susceptible to oxidation; thus, it became less preferred by the consumers [19].

Many researchers studied the possibilities of using fodder shrubs and agro-industrial by-products as alternative feed resources [21] or as a natural antioxidant [22]. However, references on the effect of MR in ruminants feed on meat properties are nonexistent. Therefore, the aim of this study was to evaluate the physicochemical quality and oxidative stability for the meat of culled ewes fed hay and concentrate as control compared to that fed MR as a total substitute to hay (Myrt-H) or partial substitute to concentrate (Myrt-C).

\section{Results}

\subsection{Meat Chemical Composition and $\alpha$-Tocopherol Content}

No differences attributable to the dietary treatment were observed for meat proximate composition or cholesterol amount. The intramuscular fat content was about $20 \% \mathrm{DM}$, while protein content averaged $71 \% \mathrm{DM}$ in all groups. However, polyphenols and $\alpha$-tocopherol contents were higher $(p<0.01)$ for the meat of both MR groups than the control (Table 1).

Table 1. Antioxidant activity and chemical composition (\% DM) of meat from ewes fed myrtle residues.

\begin{tabular}{cccccc}
\hline & $\mathrm{C}$ & Myrt-H & Myrt-C & $p$ & SEM \\
\hline Polyphenols & $53.02^{\mathrm{c}}$ & $72.07^{\mathrm{a}}$ & $68.74^{\mathrm{b}}$ & 0.04 & 5.87 \\
ABTS & $0.90^{\mathrm{b}}$ & $0.89^{\mathrm{a}}$ & 0.86 & 0.74 & 0.01 \\
$\alpha$-tocopherol $(\mu \mathrm{g} / \mathrm{g} \mathrm{DM})$ & $3.04^{\mathrm{b}}$ & $9.38^{\mathrm{a}}$ & $8.05^{\mathrm{a}}$ & $<0.01$ & 1.93 \\
$\boldsymbol{\gamma}$-tocopherol $(\mu \mathrm{g} / \mathrm{g} \mathrm{DM})$ & $0.27^{\mathrm{a}}$ & $0.16^{\mathrm{b}}$ & $0.19^{\mathrm{b}}$ & 0.01 & 0.03 \\
Cholesterol $(\mathrm{mg} / \mathrm{g})$ & 1.96 & 2.05 & 2.05 & 0.86 & 0.03 \\
Dry matter & 28.19 & 27.38 & 27.68 & 0.72 & 0.23 \\
Ash $(\% \mathrm{DM})$ & 4.60 & 4.59 & 4.60 & 0.10 & 0.03 \\
Protein $(\% \mathrm{DM})$ & 71.50 & 71.60 & 71.30 & 0.58 & 0.09 \\
Fat $(\% \mathrm{DM})$ & 23.90 & 23.81 & 24.1 & 0.48 & 0.08 \\
\hline
\end{tabular}

C: Control group receiving oat hay and concentrate; Myrt-H: group receiving pellets containing $87 \%$ myrtle residues (MR); Myrt-C: group receiving pellets containing 30\% MR; a. b. c: different letters within the same row (different diet) differ significantly $(p<0.05)$. 


\subsection{Lipid Oxidation and Color Stability of Meat during Refrigerated Storage}

Thiobarbituric acid reactive substances (TBARS) values were significantly affected by diet and storage time (Table 2). At day 0, no differences were found between dietary treatments. The meat of both MR groups was kept constant with low values that ranged between 0.35 and $0.57 \mathrm{mg} \mathrm{MDA} / \mathrm{kg}$ until day 3 to reach 1.2 and $1.06 \mathrm{mg}$ MDA/kg at day 9 of storage for Myrt-H and Myrt-C, respectively. However, the meat of $C$ group had values above $1 \mathrm{mg} \mathrm{MDA} / \mathrm{kg}$ since day 3 and reached values of more than $1.5 \mathrm{mg} \mathrm{MDA} / \mathrm{kg}$ at the end of the storage time.

Table 2. Color parameters and lipid oxidation evolution of meat from ewes fed myrtle residues.

\begin{tabular}{|c|c|c|c|c|c|c|c|c|c|}
\hline & Diet & Day 0 & Day 3 & Day 6 & Day 9 & $p$ Diet & $p$ Time & $\begin{array}{c}p \text { Diet } \\
\text { Time }\end{array}$ & SEM \\
\hline & C & $0.42^{\mathrm{a}}$ & 1.11 by & 1.58 су & $1.98 \mathrm{cy}$ & & & & \\
\hline \multirow{3}{*}{ TBARS } & Myrt-H & $0.35^{\mathrm{a}}$ & 0.57 ax & $0.78^{a x}$ & $1.2^{b x}$ & 0.01 & 0.01 & 0.14 & 0.20 \\
\hline & Myrt-C & $0.43^{\mathrm{a}}$ & $0.46^{a x}$ & $0.62^{\mathrm{ax}}$ & $1.06^{b x}$ & & & & \\
\hline & C & 35.49 & 34.29 & 33.47 & $32.71 \mathrm{y}$ & & & & \\
\hline \multirow{3}{*}{$\mathbf{L}^{*}$} & Myrt-H & $33.32^{\mathrm{a}}$ & $32.67^{\mathrm{a}}$ & $31.21^{b}$ & $30.45^{\mathrm{bz}}$ & 0.26 & 0.05 & 0.10 & 1.32 \\
\hline & Myrt-C & 37.77 & 37.15 & 36.3 & $34.8^{x}$ & & & & \\
\hline & C & $17.24^{\mathrm{a}}$ & $16.45^{\mathrm{a}}$ & $15.96^{\mathrm{a}}$ & $12.96^{\text {by }}$ & & & & \\
\hline \multirow[t]{3}{*}{$a^{*}$} & Myrt-H & $16.4^{\mathrm{a}}$ & $15.9^{\mathrm{a}}$ & $15.38^{\mathrm{a}}$ & $14.37^{b x}$ & 0.99 & 0.05 & 0.50 & 0.04 \\
\hline & Myrt-C & $16.75^{a}$ & $16.27^{\mathrm{a}}$ & $15.26^{\mathrm{a}}$ & $14.02^{b x}$ & & & & \\
\hline & C & $6.74^{\mathrm{a}}$ & $6.55^{\mathrm{a}}$ & $5.94^{\mathrm{a}}$ & $5.68^{\mathrm{ax}}$ & & & & 0.29 \\
\hline \multirow[t]{2}{*}{$b^{*}$} & Myrt-H & $6.28^{\mathrm{a}}$ & $5.87^{\mathrm{a}}$ & $5.45^{\mathrm{ax}}$ & $4.8^{\text {by }}$ & 0.77 & 0.05 & 0.60 & \\
\hline & Myrt-C & $5.92^{\mathrm{a}}$ & $5.53^{\mathrm{a}}$ & $4.93^{a b x}$ & $4.55^{\text {by }}$ & & & & \\
\hline \multicolumn{10}{|l|}{ Color change } \\
\hline \multirow{3}{*}{$\Delta \mathrm{E}^{*}$} & C & 5.23 & & & & & & & \\
\hline & Myrt-H & 3.81 & & & & & & & \\
\hline & Myrt-C & 4.26 & & & & & & & \\
\hline
\end{tabular}

C: Control group receiving oat hay and concentrate; Myrt-H: group receiving pellets containing $87 \%$ myrtle residues (MR); Myrt-C: group receiving pellets containing 30\% MR; $L$ * (lightness); * (redness); $b$ * (yellowness); a. b. c: different letters within the same row (different storage days) differ significantly $(p<0.05)$; x. y. z: different letters within same columns (different diets) differ significantly $(p<0.05) ; \Delta \mathrm{E}^{*}$ : total color change for each group during storage.

Neither MR supplementation nor the interactions between storage time and diet have a significant effect $(p>0.05)$ on meat color parameters (Table 2). Hence, all parameters had similar values for all groups. However, the color parameters significantly decreased during the storage time. During storage, $\Delta \mathrm{E} *$ ranged between 3.81 and 5.23, which was recorded for Myrt-H and $\mathrm{C}$ groups, respectively.

\subsection{Fatty Acids Profile}

The lipid meat's individual FA, the class of FA, and ratios are presented in Tables 3 and 4. For all groups, the SFA and MUFA represent around $89 \%$ of the quantified FA, where oleic acid (C18:1-9) was the most abundant with a mean percentage of $31.2 \%$, followed by palmitic acid (C16:0) and stearic acid (C18:0). The level of branched fatty acid (BCFA) was similar among all groups. No significant difference was recorded for the sum of SFA, MUFA, and PUFA contents among treatments (Table 4). The concentration of total detected conjugated linoleic acid (CLA) isomers was low for all groups. The linoleic fatty acid (C18:2 n-6) content was significantly higher for the Myrt-H group (Table 3). For total trans-18:1 and individual isomers content, no differences were observed among groups, except for trans-11 C18:1, vaccenic acid (VA) where the Myrt-H group presented the highest concentration $(p<0.05)$.

The Myrt-H group had the lowest values of C18:1-10t/C18:1-11t ratio $(p<0.05)$. The meat of the Myrt-H group presented a higher $(p<0.05) n-6 / n-3$ PUFA ratio (Table 4$)$, and it tends to have the highest level of PUFA n-6 among all groups. The levels of minor n-6 PUFA, C20:3 n-6, and C20:4 n-6 ARA were significantly higher for Myrt-H. The concentration of long-chain n-3 PUFA including 20:5n-3 (EPA), 22:5n-3 (DPA), and 22:6n-3 (DHA) was not modified due to MR supplementation. The desirable fatty acids (DFA) content tends to be higher $(p=0.08)$ for the $\mathrm{C}$ and Myrt-H groups, with $65.62 \%$ and $64.52 \%$, respectively (Table 4 ). 
Table 3. Fatty acid profile (\% of total fatty acid methyl esters (FAME)) of meat from ewes fed myrtle residues.

\begin{tabular}{|c|c|c|c|c|c|}
\hline Item & $\mathrm{C}$ & Myrt-H & Myrt-C & $p$ & SEM \\
\hline \multicolumn{6}{|l|}{ SFA } \\
\hline C10:0 & 0.35 & 0.43 & 0.45 & 0.45 & 0.03 \\
\hline $\mathrm{C} 12: 0$ & 0.10 & 0.11 & 0.11 & 0.66 & 0.003 \\
\hline C14:0 & 2.11 & 2.30 & 2.19 & 0.66 & 0.06 \\
\hline C15:0 & 0.42 & 0.42 & 0.34 & 0.17 & 0.03 \\
\hline C16:0 & 24.51 & 24.99 & 26.25 & 0.13 & 0.52 \\
\hline C17:0 & 1.28 & 1.28 & 1.07 & 0.19 & 0.07 \\
\hline C18:0 & 15.69 & 16.52 & 15.81 & 0.56 & 0.26 \\
\hline C19:0 & 0.12 & 0.10 & 0.08 & 0.41 & 0.01 \\
\hline C20:0 & 0.10 & 0.09 & 0.11 & 0.082 & 0.01 \\
\hline C22:0 & 0.04 & 0.04 & 0.05 & 0.82 & 0.002 \\
\hline \multicolumn{6}{|l|}{ MUFA } \\
\hline C14:1 & 0.07 & 0.08 & 0.08 & 0.80 & 0.05 \\
\hline C16:1 cis 9 & 1.31 & 1.34 & 1.49 & 0.48 & 0.003 \\
\hline $\mathrm{C} 16: 1$ trans 9 & 0.02 & 0.01 & 0.02 & 0.31 & 0.002 \\
\hline C16:1 trans10 & 0.06 & 0.05 & 0.06 & 0.90 & 0.02 \\
\hline C17:1 cis 9 & 0.16 & 0.12 & 0.11 & 0.56 & 0.74 \\
\hline C18:1 cis 9 & 32.56 & 30.00 & 31.08 & 0.43 & 0.03 \\
\hline C18:1 cis 11 & 1.30 & 1.37 & 1.28 & 0.54 & 0.005 \\
\hline C18:1 cis 12 & 0.20 & 0.22 & 0.21 & 0.86 & 0.0014 \\
\hline C18:1 cis 13 & 0.13 & 0.13 & 0.12 & 0.97 & 0.02 \\
\hline C18:1 cis 14 & 0.16 & 0.12 & 0.10 & 0.11 & 0.004 \\
\hline C18:1 cis 15 & 0.05 & 0.05 & 0.03 & 0.08 & 0.006 \\
\hline C18:1 trans5 & 0.01 & 0.01 & 0.03 & 0.18 & 0.01 \\
\hline C18:1 trans 9 & 0.19 & 0.15 & 0.17 & 0.49 & 0.13 \\
\hline C18:1 trans10 & 0.56 & 0.89 & 0.48 & 0.1 & 0.09 \\
\hline C18:1 trans 11 & $0.48^{\mathrm{b}}$ & $0.74^{\mathrm{a}}$ & $0.49^{b}$ & 0.04 & 0.01 \\
\hline C18:1 trans 12 & 0.13 & 0.11 & 0.10 & 0.27 & 0.73 \\
\hline$\sum$ trans C18:1 & 1.77 & 1.73 & 1.38 & 0.35 & 0.12 \\
\hline \multicolumn{6}{|l|}{ PUFA } \\
\hline C18:2 n-6 & $4.48^{\mathrm{b}}$ & $6.13^{\mathrm{a}}$ & $4.69^{b}$ & 0.01 & 0.52 \\
\hline $\begin{array}{c}\text { C18:2 trans } 10 . \text { cis } 12 \\
\text { CLA }\end{array}$ & 0.04 & 0.05 & 0.05 & 0.40 & 0.003 \\
\hline C18:2 cis7. cis9 CLA & 0.01 & 0.01 & 0.01 & 0.92 & 0.002 \\
\hline $\begin{array}{c}\text { C18:2 cis } 9 . \text { trans } 11 \\
\text { CLA }\end{array}$ & 0.32 & 0.22 & 0.24 & 0.26 & 0.03 \\
\hline C18:2 trans9. cis 11 CLA & 0.05 & 0.07 & 0.07 & 0.44 & 0.01 \\
\hline C18:2 cis 1 . trans 1 CLA & 0.01 & 0.01 & 0.01 & 0.93 & 0.00 \\
\hline C18:3 n-3 & 0.51 & 0.53 & 0.44 & 0.22 & 0.01 \\
\hline C18:3 n-6 & 0.05 & 0.06 & 0.06 & 0.53 & 0.03 \\
\hline C20:2 n-6 & 0.05 & 0.06 & 0.05 & 0.35 & 0.003 \\
\hline C20:3 n-9 & 0.32 & 0.35 & 0.33 & 0.64 & 0.01 \\
\hline C20:3 n-6 & $0.16^{b}$ & $0.24^{\mathrm{a}}$ & $0.18^{b}$ & 0.05 & 0.01 \\
\hline C20:4 n-6 ARA & $1.67^{b}$ & $2.21^{\mathrm{a}}$ & $1.75^{\mathrm{b}}$ & 0.04 & 0.03 \\
\hline C20:5 n3 EPA & 0.17 & 0.18 & 0.22 & 0.53 & 0.17 \\
\hline C22:4 n-6 & 0.12 & 0.13 & 0.13 & 0.88 & 0.02 \\
\hline C22:5 n-3 DPA & 0.36 & 0.37 & 0.40 & 0.94 & 0.01 \\
\hline C22:6 n-3 DHA & 0.12 & 0.12 & 0.14 & 0.82 & 0.01 \\
\hline
\end{tabular}

C: Control group receiving oat hay and concentrate; Myrt-H: group receiving pellets containing $87 \%$ myrtle residues (MR); Myrt-C: group receiving pellets containing 30\% MR; SFA: saturated fatty acids; MUFA: monounsaturated fatty acids; PUFA: polyunsaturated fatty acids; a. b.: different letters within the same row (different diets) differ significantly $(p<0.05)$. 
Table 4. Fatty acid groups (\% of total FAME) and ratios of meat from ewes fed myrtle residues.

\begin{tabular}{cccccc}
\hline Item & C & Myrt-H & Myrt-C & $p$ & SEM \\
\hline ¿SFA & 50.91 & 51.17 & 52.24 & 0.4 & 0.41 \\
¿cis_MUFA & 37.83 & 35.45 & 36.54 & 0.44 & 0.69 \\
¿trans_MUFA & 2.02 & 1.93 & 1.58 & 0.37 & 0.13 \\
¿MUFA & 39.85 & 37.38 & 38.12 & 0.49 & 0.73 \\
¿CLA & 0.46 & 0.39 & 0.41 & 0.56 & 0.02 \\
BCFA & 1.99 & 1.80 & 1.82 & 0.23 & 0.06 \\
¿PUFA & 9.25 & 11.46 & 9.64 & 0.36 & 0.68 \\
¿PUFA n-6 & 5.19 & 8.87 & 6.04 & 0.06 & 1.11 \\
¿PUFA n-3 & 1.16 & 1.21 & 1.20 & 0.96 & 0.02 \\
18:1 10t/C18:1 11t & $1.97^{\mathrm{b}}$ & $0.78^{\mathrm{a}}$ & $1.14^{\mathrm{b}}$ & 0.04 & 0.15 \\
DFA & 64.79 & 65.36 & 63.57 & 0.08 & 0.59 \\
PUFA/SFA & 0.18 & 0.22 & 0.19 & 0.33 & 0.01 \\
n-6/n-3 & $5.63^{\mathrm{b}}$ & $7.20^{\mathrm{a}}$ & $5.85^{\mathrm{b}}$ & 0.03 & 0.49 \\
AI & 0.69 & 0.73 & 0.76 & 0.27 & 0.02 \\
TI & 1.61 & 1.61 & 1.69 & 0.57 & 0.03
\end{tabular}

C: Control group receiving oat hay and concentrate; Myrt-H: group receiving pellets containing $87 \%$ myrtle residues (MR); Myrt-C: group receiving pellets containing 30\% MR; SFA: saturated fatty acids; MUFA: monounsaturated fatty acids; PUFA: polyunsaturated fatty acids; CLA: conjugated linoleic acids; DFA: desirable fatty acids; TI: thrombogenicity index; AI: atherogenicity index. a. b.: different letters within the same row differ significantly $(p<0.05)$.

\section{Discussion}

The similarity in meat chemical composition among groups may be due to the similarity of the animal's slaughter body weight [23]. In a recent study, Yagoubi et al. [15] have reported higher protein content and less intramuscular fat content in lamb's meat when animals were fed rosemary distillation residues. Hence, adding linseed oil and natural Vitamin E into ewes' diet has proven to only affect lamb meat's fat and ash content [24]. The higher antioxidant ability of meat during storage for MR groups may be explained by the higher total phenolic content (TPC) and DPPH radical scavenging ability in both MR pellets (M-Hay and M-Conc) compared to hay and concentrate (Table 5). Several authors have reported the effect of animal's diet rich in TPC on their meat's polyphenols and tocopherol's content. Moñino et al. [1] showed a positive transfer of polyphenols to lamb meat when ewes were fed rosemary by-product. Similar results were found with lambs fed rosemary residues rich in polyphenols [15]. Despite the presence of other tocopherols, $\alpha$-tocopherol is the principal component of the vitamin E activity. It was shown that $\alpha$-tocopherol can be used as an antioxidant in animal's diet, since it has the capacity to delay meat oxidation. In fact, $\alpha$-tocopherols are not degraded in the rumen but instead are deposited in muscle cell membranes where their antioxidant actions are more effective $[25,26]$. This finding is in agreement with Gómez-Cortés et al. [26], who found a similar result with lamb meat when ewes were fed grape pomace. Hence, several authors reported the effect of dietary supplementation on muscle's $\alpha$-tocopherol content. Ripoll et al. [27] found an increase in muscle's $\alpha$-tocopherol content when lambs received $\alpha$-tocopherol supply; the same tendency was observed with meat produced on pasture and fresh forage, which are rich in $\alpha$-tocopherol [28]. In reverse, the linseed oil supply did not affect the vitamin E levels in ewes meat [24]. The meat lipid oxidation was decreased by feeding MR to ewes. The decrease of TBARS values during storage in both MR groups may be explained by the presence of $\alpha$-tocopherol, which is known for its antioxidant ability [25], explaining the high correlation between TBARS and $\alpha$-tocopherol values $\left(\mathrm{r}^{2}=0.95\right)$. These results are in concordance with the polyphenols and $\alpha$-tocopherols content previously reported for the current study. Polyphenols are also proven to have strong antioxidant effects against reactive oxygen species and free radical attacks in biological systems and in foods [29]. Several authors mentioned that polyphenols have the ability to prevent muscle tissues from oxidation [26]. Similar results were found by other researchers on the meat lipid oxidation delay by rosemary residues supply to lamb $[15,30]$. Escalante et al. [31] explained this result by the ability of rosemary extract to chelate metal ions, which lead to a decrease in the formation rate of activated oxygen. In this context, Kerry et al. [32] confirmed that the dietary antioxidants incorporated within cell membranes are more efficient than those added post mortem to preserve meat products from oxidative damage and to extend their shelf life. Hence, Moñino et al. [1] showed that phenolic compounds can be transferred to lamb meat from ewe fed rosemary distillate 
leaves. Phenolic compounds might have an indirect antioxidant effect, since they can chelate pro-oxidant metals and reduce the production of peroxides [33]. Color loss during storage may be attributed to the oxidation process in the presence of oxygen. In fact, the lightness is mostly associated with muscle and protein structures, which influence the water holding capacity [34]. The oxidation can cause an increase in cell membrane permeability and thus a decrease in the water holding capacity of myofibrils, and, as a consequence, more juice loss from the meat and an increase in $\mathrm{L}^{*}$ [35]. At the end of the storage, the meat of the Myrt-H and control groups had the highest value of redness $\left(a^{*}\right)$ and yellowness $\left(b^{*}\right)$, respectively. Our results are in agreement with those of Realini et al. [36], who showed no feeding effect on meat color parameters. The effects of animal diet on color have been largely described in fresh meat [13]. In addition, it was shown that meat's color stability is associated to oxidation [37], and that rosemary residues, with high antioxidant power, extended the sausages' color stability during storage [10]. Color differences $\left(\Delta \mathrm{E}^{*}\right)$ are described in the National Bureau of Standards Unit (NBS unit) and state that there are small differences between colors, which are detectable by humans: $0-0.5$ trace, $0.5-1.5$ slight, 1.5-3.0 noticeable, 3.0-6.0 appreciable differences, 6.0> obvious difference. Based on those standards, in the current study, color changes were perceptible, especially with the $\mathrm{C}$ group, where $\left(\Delta \mathrm{E}^{*}\right)$ was around 5.32 . These results confirm that storage time did have a significant effect on meat's color, which was more noticeable with $\mathrm{C}$ group samples.

Table 5. Feedstuffs' antioxidant potential, fatty acids profile (\% of total FAME), and chemical composition.

\begin{tabular}{|c|c|c|c|c|c|}
\hline \multirow[b]{2}{*}{ Antioxidant and Radical Scavenging Activities } & \multicolumn{5}{|c|}{ Ingredients } \\
\hline & Hay & Concentrate & MR & M-Hay & M-Conc \\
\hline $\mathrm{TPC}(\mathrm{mg} \mathrm{TAE} / \mathrm{g})$ & 6.88 & 3.07 & 153.43 & 72.4 & 25.17 \\
\hline DPPH radical scavenging activity (mg TE/g) & 17.8 & 17.78 & 670.47 & 242.24 & 127.16 \\
\hline ABTS radical scavenging ability (mg TE/g) & 16.2 & 4.0 & 406.00 & 305.53 & 194.27 \\
\hline \multicolumn{6}{|c|}{ Fatty Acids (\%) } \\
\hline C18:0 & 17.00 & 8.14 & 11.52 & 11.07 & 9.43 \\
\hline C18:2-n6 & 16.64 & 45.19 & 34.27 & 31.59 & 40.98 \\
\hline C18:3-n3 & 6.33 & 3.20 & 4.75 & 7.05 & 4.72 \\
\hline SFA & 58.44 & 35.70 & 44.11 & 40.92 & 38.19 \\
\hline MUFA & 18.58 & 15.91 & 16.87 & 20.44 & 16.11 \\
\hline PUFA & 22.98 & 48.39 & 39.02 & 38.64 & 45.70 \\
\hline n6 & 16.64 & 45.19 & 34.27 & 31.59 & 40.98 \\
\hline n3 & 6.33 & 3.20 & 4.75 & 7.05 & 4.72 \\
\hline n6/n3 & 16.64 & 45.19 & 34.27 & 31.59 & 40.98 \\
\hline \multicolumn{6}{|c|}{ Nutritional Composition } \\
\hline Dry matter & 90.1 & 92.6 & 91.8 & 93 & 92.1 \\
\hline Crude protein & 5.1 & 12.9 & - & 10.6 & 14.9 \\
\hline Total ash & 6.2 & 2.6 & - & 5 & 8.5 \\
\hline $\mathrm{NDF}$ & 63.8 & 44.98 & 33.56 & 37.59 & 30.85 \\
\hline $\mathrm{ADF}$ & 36.39 & 10.21 & 24.11 & 20.69 & 11.29 \\
\hline ADL & 3.49 & 1.25 & 8.78 & 5.99 & 2.91 \\
\hline Tannins (mg TAE/g) & 6.88 & 3.07 & 153.43 & 72.41 & 25.17 \\
\hline
\end{tabular}

MR: distillate myrtle leaves; M-Hay: pellets containing $87 \%$ of myrtle residues (MR); M-Conc: pellets containing $30 \%$ of MR.

Lipid auto-oxidation products were found to increase oxy-myoglobin oxidation [38]; thus, the incorporation of dietary plant extract may inhibit color degradation. Studying the incorporation of grape pomace and linseed oil into ewes' diet, Gómez-Cortés et al. [26] and Gallardo et al. [24] reported 
that polyphenols supply can inhibit color deterioration during storage due to their ability to reduce myoglobin oxidation.

The results on the prevalence of oleic, stearic, and palmitic FA in sheep meat is in concordance with the literature [11,36,39]. From a nutritional point of view, the MR supply had a positive effect since palmitic acid (C16:0) and myristic acid (C14:0) present lower concentrations in MR groups. In fact, SFA with lengths from 12 to 16 carbons can raise cholesterol concentration and increase inflammation and risks for Cardiovascular disease (CVD) in human [4]. The similarity in BCFA among groups may be due to the fact that all diet had similar carbohydrate contents; in fact, BCFA are synthetized from the propionate originated in the rumen by the fermentation of dietary carbohydrate [40]. Similar results were found on meat from lambs supplied by linseed and quercetin [39]. However, several authors found that animal's diet affected the BCFA content in ruminant products. The meat of lambs fed concentrate had a higher BCFA concentration than the meat of lambs fed on pasture [41]. These FA are responsible for the distinctive sheepy flavor and odor in meat, which are considered important factors for consumers [40]. Hence, an undesirable flavor of cooked meat may be attributed to their medium-chain fatty acids content, especially, 4-methyloctanoic and 4-methylnonanoic acids [42]; in the current study, these compounds have not been identified. The low concentration of total CLA detected in the meat from all groups could be due to the dietary PUFA conversion in the rumen [24]. Myrt-H had the lowest values of C18:1-10t/C18:1-11t ratio due to its higher vaccenic acid content (C18:1 trans11). Gómez-Cortés et al. [26] explained similar results by the absence of changes on the ruminal biohydrogenation pathway, which leads to an accumulation of vaccenic acid in the meat. Human trans FA intake should be as low as possible, considering their negative potential effect on human health [43]. Thus, the MR diet improved meat's VA content, which is known for their health benefits. An improvement was recorded in lamb meat's trans FA content when the ewe diet was supplemented with linseed oil and vitamin E [24]. The higher n-6/n-3 PUFA ratio and PUFA n-6 content may be associated to the $n-6 / n-3$ PUFA dietary ratio and PUFA $n-6$ content in feedstuffs [44]. Diets with thyme leaves, rosemary residues, or rosemary essential oil resulted in a decrease in the $n-6 / n-3$ ratio in lamb meat $[11,14,21]$. Meanwhile, Resconi et al. [45] found no significant difference in $n-6 / n-3$ ratio in meat from suckling lambs reared by ewes fed grape pomace and grape seed. On the other hand, Myrt-H had higher levels of Vitamin E; in fact, Enser et al. [46] reported that vitamin E concentration and n-6 levels are associated, which suggest that higher levels of antioxidant inhibited PUFA loss. The diets used in this study did not affect the long chain n-3 PUFA content. Guerrero et al. [47] reported a lack of effect of linseed administration, into cull ewes diet, on EPA and DHA concentrations. They explained this result by the competition between $\alpha$-linolenic acid and the precursor for DHA for the activity of the $\Delta 6$ desaturase enzyme. However, long-chain n-6 PUFA was significantly affected by the diet, where Myrt-H had the highest C20:3 n- 6 and C20:4 n-6 ARA content $(p<0.05)$. The thrombogenic index (TI) and atherogenic index (AI) were not affected by the dietary treatment. The TI averaged 1.6 for all groups, while AI values varied between 0.69 for the $C$ group and 0.76 for the Myrt-C group. Similar AI values were also found by Nieto et al. [14] in lamb's meat when ewes were fed thyme leaves in the diet. Myrt-H samples also tend to have the highest DFA content. This result may be explained by the higher C18:0 and PUFA content. PUFA are the most sensitive to oxidation due to the presence of double bonds in the hydrocarbon chain [48]. Thus, PUFA are more exposed to oxidative reactions, since they constitute a part of the phospholipids located in cellular membranes [49]. Dietary supplementation, which has beneficial effects on meat's antioxidant stability, may influence the PUFA content. Thus, due to its high content in polyphenols, the Myrt-H diet maintained the unsaturated FA level in cell membranes, particularly C20:3 n-6, C20:4 n-6 ARA, and vaccenic acid content (C18:1 trans11) [50]. Similarly, Recsan et al. [51] reported that dietary supplementation with aromatic plant essential oil did protect PUFA against oxidation in cell membrane. 


\section{Material and Methods}

\subsection{Diets, Animals, Experimental Design, and Slaughter Procedure}

All the procedures employed in this study (transport and slaughtering) meet ethical guidelines and adhere to Tunisian legal requirements in accordance with Law no. 2005-95 of 18 October 2005 (Chapter II; Sections 1 and 2 relative to the slaughter of animals).

The MR were collected from a distillation unit in the Northwest of Tunisia (Nefza) and then air-dried to ensure complete dehydration. Then, dried MR were ground and mixed with other ingredients to make two types of pellets. The M-Hay pellets were composed from $87 \%$ MR and $13 \%$ bran to have a feed similar to oat hay. The M-Conc pellets contain 30\% MR, 12\% soy, and 58\% barley; it is equivalent to a concentrate. Twenty-seven Barbarine culled ewes ( $35 \mathrm{~kg}$ of body weight, BW) were divided into three homogenous groups of 9 each and were reared in individual pens. Sheep in the control group (C) received $750 \mathrm{~g}$ of concentrate and $500 \mathrm{~g}$ of hay. The Myrt-H group received $750 \mathrm{~g}$ of concentrate and $500 \mathrm{~g}$ of M-Hay as a whole substitute to hay. The Myrt-C group received $500 \mathrm{~g}$ of oat-hay, $350 \mathrm{~g}$ of concentrate, and $400 \mathrm{~g}$ of M-Conc in partial substitution to concentrate. The feed's antioxidant potential and nutritional composition are shown in Table 5. All ewes were slaughtered at similar BW $(41.5 \mathrm{~kg})$ at the end of the fattening period, which lasted 90 days. After cooling at $4{ }^{\circ} \mathrm{C}$ during $24 \mathrm{~h}$, carcasses were divided into two halves, and the Longissimus thoracis and lumborum (LTL) muscle was extracted from the left side for meat analysis.

\subsection{Meat Samples Preparation and Measurements}

Samples of Longissimus thoracis and lumborum (LTL) muscle were stored at $-20{ }^{\circ} \mathrm{C}$ for Vitamin $\mathrm{E}$ and FA analysis. A section of LTL muscle was cut into four $2.5 \mathrm{~cm}$ thick slices, wrapped with an oxygen-permeable polyvinylchloride film, randomly assigned to four 4 trays $(0,3,6$, or $9 \mathrm{~d}$ of storage), and kept in darkness at $4{ }^{\circ} \mathrm{C}$. Immediately after color measurement, the samples were packed and frozen $\left(-20{ }^{\circ} \mathrm{C}\right)$ until TBARS analysis. In another section, the initial $\mathrm{pH}$ and ultimate $\mathrm{pH}(1 \mathrm{~h}$ and $24 \mathrm{~h}$ after slaughter, respectively) were measured with a penetrating electrode connected to a $\mathrm{pH}$ meter (HI 99163; Hanna Instruments, Sălaj, Romania) and calibrated with two buffers (7.00 and 4.01) at $25^{\circ} \mathrm{C}$.

To evaluate color, a Minolta spectrophotometer (CM-2006 d; Konica Minolta Holdings, Inc., Osaka, Japan) was used directly on the muscle surface with a measured area of $8 \mathrm{~mm}$, standard illuminant D65, and an observer angle of $10^{\circ}$. The lightness $\left(\mathrm{L}^{*}\right)$, redness $\left(\mathrm{a}^{*}\right)$, and yellowness $\left(\mathrm{b}^{*}\right)$ were recorded. Hence, $\left(\Delta \mathrm{E}^{*}\right)$ was calculated in order to estimate the color change during storage time, using the following equations: $\Delta \mathrm{E}^{*}=\left[\left(\mathrm{L}_{0}-\mathrm{L}_{\mathrm{t}}\right)^{2}+\left(\mathrm{a}_{0}-\mathrm{a}_{\mathrm{t}}\right)^{2}+\left(\mathrm{b}_{0}-\mathrm{b}_{\mathrm{t}}^{2}\right)\right]^{1 / 2}$, where 0 is the value at day 0 and $t$ is the value at day 9 [52]. Results were expressed according to the CIE L * $a^{*} b^{*}$ system (CIE, 1976) as the average of three measurements performed on a cut surface area. For chemical composition, samples of meat were lyophilized to obtain dry matter (DM); then, samples were ground (1 mm screen). On homogenized ground samples, ash was determined by incineration at $600{ }^{\circ} \mathrm{C}$ for $8 \mathrm{~h}$, nitrogen was determined by the Kejeldahl method, and then, the crude protein content was calculated as $\mathrm{N} \times 6.2$ [53]; the fat was extracted with petroleum ether, which was measured using AOCS Standard Procedure Am 5-04.

\subsection{Lipid Oxidation Analyses (TBARS) in Meat}

Meat lipid oxidation was assessed by the TBARS (thiobarbituric acid reactive substances) assay as determined by Botsoglou et al. [54] with modifications. First, $20 \mathrm{~mL}$ of 10\% trichloro acetic acid were added to $10 \mathrm{~g}$ of minced meat, and homogenization was carried out using an Ultra-Turrax (T25, IKA-Labortechnik, Staufen, Germany) for $10 \mathrm{~s}$ at 13,500 $\times g \mathrm{rpm}$. After homogenization, $2 \mathrm{~mL}$ of the supernatant obtained was transferred to a test tube and mixed with $2 \mathrm{~mL}$ of thiobarbituric acid solution. Test tubes were incubated at $97^{\circ} \mathrm{C}$ in a water bath for $15 \mathrm{~min}$ to develop a pink absorbance, and the absorbance of the sample was recorded against the appropriate blank at $532 \mathrm{~nm}$ by a spectrophotometer 
(Shimadzu, Tokyo, Japan). A calibration curve was prepared using 1,1,3,3-tetramethoxypropane; and TBARS values are expressed as mg malondialdehyde (MDA) equivalents $/ \mathrm{kg}$ sample.

\subsection{Total Phenolic Content (TPC) and Vitamin E Analysis}

The TPC of meat was performed, in triplicate, according to the method of Vázquez et al. [55] with modifications. To $1 \mathrm{~g}$ of ground meat, $9 \mathrm{~mL}$ of milli-Q water and $10 \mathrm{~mL}$ of aqueous solution of methanol $(50 / 50 ; v / v)$ were added and mixed for $5 \mathrm{~min}$. To the obtained mix, $500 \mu \mathrm{L}$ of Carrez I solution were added and dissolved while vortexing for $1 \mathrm{~min}$; then, $500 \mu \mathrm{L}$ of Carrez II solution were added and dissolved while vortexing for $1 \mathrm{~min}$, and finally, $5 \mathrm{~mL}$ of acetonitrile were added and dissolved. The test tubes were left to stand for $25 \mathrm{~min}$ and then centrifuged at $4000 \times \mathrm{g} \mathrm{rpm}$ for $15 \mathrm{~min}$ at $4{ }^{\circ} \mathrm{C}$. The supernatant was filtered through a $0.22 \mu \mathrm{m}$ PTFE filter in a $15 \mathrm{~mL}$ tube, and the extract obtained was used to determine TPC. The TPC in the liquid extract was estimated using the Folin-Ciocalteu method. To $15 \mu \mathrm{L}$ of extract, $147 \mu \mathrm{L}$ of water milli-Q, $13 \mu \mathrm{L}$ of Folin-Ciocalteu reagent, and $7 \% \mathrm{Na}_{2} \mathrm{CO}_{3}$ were added. Samples were held to stand for $1.5 \mathrm{~h}$ in the dark. The absorbance of samples was measured with a spectrophotometer (Thermo Electron Corporation, Spain) at $750 \mathrm{~nm}$, and the results were expressed as $\mu \mathrm{g}$ gallic acid equivalents (GAE)/g dried sample. The ABTS assay was determined following the method of Saura-Calixto and Goñi [56] with some modifications. The vitamin E analysis was performed according to the method of Prates et al. [57]. For saponification, $0.2 \mathrm{~g}$ of ascorbic acid and $3 \mathrm{~mL}$ of saponification solution were added to $0.2 \mathrm{~g}$ of lyophilized meat; the mix was placed in glass tube of $25 \mathrm{~mL}$. The saponification solution was made by mixing $10 \% w / v$ of $\mathrm{KOH}$ with $50 \% \mathrm{EtOH}$ and $50 \%$ of distilled water. The tubes were vortexed under nitrogen atmosphere, in order to eliminate the air, and then left overnight in an orbital shaker at $(600 \times \mathrm{g} \mathrm{rpm})$. In the tubes, $5 \mathrm{~mL}$ of hexane-ethyl acetate $(9: 1 v / v)$ and $5 \mu \mathrm{g} / \mathrm{mL}$ of 2,6-di-tert-butyl-4-methylphenol (BHT) were added. The mixture was shaken with a vortex for $5 \mathrm{~s}$, followed by the orbital shaker at maximum speed for $10 \mathrm{~min}$ and centrifugation for $5 \mathrm{~min}$ at $3500 \times \mathrm{g} \mathrm{rpm}$ and $10^{\circ} \mathrm{C}$ in order to separate different phases. An aliquot of the upper layer was transferred into a glass tube of $10 \mathrm{~mL}$ and then evaporated in a rotational vacuum concentrator (Christ RVC2-25) for $45 \mathrm{~min}$ at $40{ }^{\circ} \mathrm{C}$. The residue obtained was dissolved in $1 \mathrm{~mL}$ of mobile phase acetonitrile/methanol/dichlorometane (75:15:10, v:v:v). The mixture was vortexed and shaken in an orbital shaker $(600 \times \mathrm{g} \mathrm{rpm})$ for $10 \mathrm{~min}$, and the aliquot of the $\mathrm{n}$-hexane layer was filtered through a $13 \mathrm{~mm} \times 0.20 \mu \mathrm{m}$ PTFE filter into an amber screw-cap vial for UPHLC. The chromatographic system used was an Acquity UPLC H-Class liquid chromatograph composed by a fluorescence detector (Waters 2475 Multi Fluorescence Detector) and a column Acquity UPLC HSS T3 column $2.1 \mathrm{~mm} \times$ $15 \mathrm{~mm} \times 1.8 \mu \mathrm{m}$. Tocopherols and cholesterol were detected at 295 and $220 \mathrm{~nm}$, respectively.

Total phenolic content and antioxidant activity analysis in feedstuff samples was previously described in Tibaoui et al. [58].

\subsection{Fatty Acid Profile}

Meat's fatty acid methyl esters (FAME) were assessed according to the method of Lee et al. [59], with modifications. For this, $0.2 \mathrm{~g}$ of lyophilized and minced meat samples were mixed with $1 \mathrm{~mL}$ of internal standard (Methyl tricosanoate, C23:0), $2 \mathrm{~mL}$ of heptane, and $4 \mathrm{~mL}$ of $\mathrm{NaOH} / \mathrm{CH} 3 \mathrm{CH}(0.5 \mathrm{M})$. The mixture was homogenized with vortex $(30 \mathrm{~s})$ and then heated for $20 \mathrm{~min}$ at $50{ }^{\circ} \mathrm{C}$. After cooling, $4 \mathrm{~mL}$ of acetyl chloride was added $\mathrm{CH}_{3} \mathrm{OH}(1 / 10 \mathrm{v} / \mathrm{v})$, and the mixture was homogenized and heated again for $60 \mathrm{~min}$ at $50{ }^{\circ} \mathrm{C}$. After cooling at ambient temperature for a few minutes, $2 \mathrm{~mL}$ of water milli-Q was added; then, the mixture was homogenized and centrifuged for $5 \mathrm{~min}, 3500 \times \mathrm{g} \mathrm{rpm}$ at $10{ }^{\circ} \mathrm{C}$. The upper layer was extracted and deposited into $5 \mathrm{~mL}$ tubes where anhydrous $\mathrm{Na}_{2} \mathrm{SO}_{4}$ was introduced for dehydration. Then, the mixture was shaken and centrifuged for $5 \mathrm{~min}, 3500 \times \mathrm{g} \mathrm{rpm}$ at $10{ }^{\circ} \mathrm{C} ; 1 \mathrm{~mL}$ of the supernatant was transferred into a screw-cap glass vial for gas chromatography. FAME analyses were carried out by gas chromatography (GC-FID Bruker gas chromatograph) equipped with a capillary column (BR-2560). The identification of FAME was aided with the use of several reference methyl esters (GLC-532, GLC-401, GLC-642, GLC-643, GLC-538 and GLC-463) and quantified 
using the internal standard (C23:0 Methyl-tricosanoate). Saturated (SFA), monounsaturated (MUFA), and polyunsaturated fatty acids (PUFA) were calculated and reported as \% FAMEs. The desirable fatty acids were calculated as DFA $=\sum$ MUFA $+\sum$ PUFA + C18:0. The saturation index (SI) (1), atherogenic (AI) (2) and thrombogenic (TI) (3) indices were calculated according to Ulbricht and Southgate [60]:

$$
\begin{gathered}
S I=\frac{(\mathrm{C} 14: 0+\mathrm{C} 16: 0+\mathrm{C} 18: 0)}{\sum M U F A+\text { PUFA }} \\
A I=\frac{C_{12: 0}+\left(4 x C_{14: 0}\right)+C_{16: 0}}{\sum M U F A+\sum n 6+\sum n 3} \\
T I=\frac{C_{14: 0}+C_{16: 0}+C_{18: 0}}{0.5 \sum M U F A+0.5 \sum n 6+3 \sum n 3+\frac{\sum n 3}{\sum n 6}}
\end{gathered}
$$

\subsection{Statistical Analysis}

The effect of dietary treatment on the meat's FA profile, chemical composition, and antioxidant activities measured were assessed by one-way ANOVA, using the General Linear Model (GLM) procedure of SAS (2004) with Student's multiple range test, and the statistical significance was defined at $p<0.05$. For $\mathrm{pH}$, color, and TBARS measurements during storage, a Linear-Mixed model analysis was conducted, with diet, storage time, and the interaction between them as the variable factors. Mean squared errors (MSE) were determined for all analyses.

\section{Conclusions}

Meat color parameters were not affected by ewes' intake of myrtle residues. However, healthy FAs, including long-chain PUFAs such as C20:3 n-6 and C20:4 n-6 ARA, vaccenic acid, and DFA were higher in the Myrt-H goup. In addition, these residues lead to higher meat $\alpha$-tocopherol and TPC content and better lipid oxidation by lowering the TBARS values. It seems that polyphenols have the ability to transfer into muscle from the diet, which could contribute to enhancing the meat's antioxidant stability and improve its fatty acid profile. Therefore, according to the results obtained, the substitution of conventional feedstuff with a dose of $87 \%$ MR in ewes' diet could be an interesting alternative to improve the meat quality of culled ewes, being an inexpensive source of $\alpha$-tocopherol and TPC, protecting PUFA against oxidation, reducing the level of lipid oxidation, and improving color stability during storage.

Author Contributions: Conceptualization, S.S., I.E. and N.A.; Data curation, J.R.B. and M.J.; Formal analysis, S.T., I.E. and J.R.B.; Investigation, S.T., S.S. and N.A.; Methodology, M.J.; Supervision, I.E. and N.A.; Validation, N.A.; Writing-original draft, S.T.; Writing—review and editing, S.S., M.J. and N.A. All authors have read and agreed to the published version of the manuscript.

Funding: This research received no external funding.

Acknowledgments: The authors are grateful to ZinaTaghouti, technician in Animal Production laboratory in INRAT and to the technicians of CITA for their technical assistance and the staff of the experimental farm Bou-Rebiaa for the feeding experiment servicing. This work was supported by the Tunisian Ministry of High and Scientific Research through "Laboratory of Animal and Forage Production".

Conflicts of Interest: The authors declare no conflict of interest.

\section{References}

1. Moñino, M.I.; Martínez, C.; Sotomayor, J.A.; Lafuente, A.; Jordan, M.J. Polyphenolic ransmission to Segureño lamb meat from ewes dietary supplemented with the distillate from rosemary (Rosmarinus officinalis) leaves. J. Agric. Food Chem. 2008, 56, 3363-3367. [CrossRef] [PubMed]

2. Mahouachi, M.; Atti, N.; Hajji, H. Use of spineless cactus (Opuntia ficus indica f. inermis) for dairy goats and growing kids: Impacts on milk production, kid's growth and meat quality. Sci. World J. 2012, 2012. [CrossRef] 
3. Bonanno, A.; Tornambè, G.; Bellina, V.; De Pasquale, C.; Mazza, F.; Maniaci, G.; Di Grigoli, A. Effect of farming system and cheese making technology on the physicochemical characteristics, fatty acid profile, and sensory properties of Caciocavallo Palermitano cheese. Int. J. Dairy Sci. 2013, 96, 710-724. [CrossRef]

4. Mensink, R.P.; Zock, P.L.; Kester, A.D.M.; Katan, M.B. Effects of dietary fatty acids and carbohydrates on the ratio of serum total to HDL cholesterol and on serum lipids and apolipoproteins: A meta-analysis of 60 controlled trials. Am. J. Clin. Nutr. 2003, 77, 1146-1155.

5. Carballo, D.E.; Caro, I.; Andrés, S.; Giráldez, F.J.; Mateo, J. Assessment of the antioxidant effect of astaxanthin in fresh, frozen and cooked lamb patties. Food Res. Int. 2018, 111, 342-350. [PubMed]

6. Cunha, L.C.M.; Monteiro, M.L.G.; Lorenzo, J.M.; Munekata, P.E.S.; Muchenje, V.; de Carvalho, F.A.L.; Conte-Junior, C.A. Natural antioxidants in processing and storage stability of sheep and goat meat products. Food Res. Int. 2018, 111, 379-390.

7. Kanner, J.; Hazan, B.; Doll, L. Catalytic 'free' iron ions in muscle foods. J. Agric. Food Chem. 1991, 36, 412-415.

8. Ito, N.; Fukushinma, S.; Hasegawa, A.; Shibata, M.; Ogiso, T. Carcinogenicity of butylated hydroxy anisole in F344 rats. J. Natl. Cancer Inst. 1983, 70, 343-347.

9. Manso, T.; Gallardo, B.; Guerra-Rivas, C. Modifying milk and meat fat quality through feed changes. Small Rumin. Res. 2016, 142, 31-37.

10. Ben Abdelmalek, Y.; Essid, I.; Smeti, S.; Atti, N. The anti-oxidant and antimicrobial effect of Rosmarinus officinalis L. distillation residues' intake on cooked sausages from ewes fed linseed. Small Rumin. Res. 2018, 168, 87-93.

11. Smeti, S.; Hajji, H.; Mekki, I.; Mahouachi, M.; Atti, N. Effects of dose and administration form of rosemary essential oils on meat quality and fatty acid profile of lamb. Small Rumin. Res. 2018, 158, 62-68. [CrossRef]

12. Ranucci, D.; Miraglia, D.; Trabalza-Marinucci, M.; Acuti, G.; Codini, M.; Ceccarini, M.R.; Branciari, R. Dietary effects of oregano (Origanum vulgaris L.) plant or sweet chestnut (Castanea sativa Mill.) wood extracts on microbiological, chemico-physical characteristics and lipid oxidation of cooked ham during storage. Ital. J. Food Saf. 2015, 4, 216-219.

13. Smeti, S.; Atti, N.; Mahouachi, M. Effects of finishing lambs in rich aromatic plant pasture or in feedlot on lamb growth and meat quality. J. Appl. Anim. Res. 2014, 42, 297-303. [CrossRef]

14. Nieto, G.; Bañón, S.; Garrido, M.D. Incorporation of thyme leaves in the diet of pregnant and lactating ewes: Effect on the fatty acid profile of lamb. Small Rumin. Res. 2012, 105, 140-147. [CrossRef]

15. Yagoubi, Y.; Joy, M.; Ripoll, G.; Mahouachi, M.; Bertolín, J.R.; Atti, N. Rosemary distillation residues reduce lipid oxidation, increase alphatocopherol content and improve fatty acid profile of lamb meat. Meat Sci. 2018, 136, 23-29. [CrossRef]

16. Mahmoudi, B.M.; Salehi, A.; Sharifi, S.D. Growth Performance, Carcass Characteristics, Antibody Titer and Blood Parameters in Broiler Chickens Fed Dietary Myrtle (Myrtus communis) Essential Oil as an Alternative to Antibiotic Growth Promoter. Poult. Sci. J. 2014, 2, 37-49.

17. Birick, H.; Yesilbag, D.; Gezen, S.S.; Bulbul, T. Effects of dietary myrtle oil (Myrtus communis L.) supplementation on growth performance, meat oxidative stability, meat quality and erythrocyte parameters in quails. Rev. Med. Vet. 2012, 163, 131-138.

18. Mebirouk-Boudechiche, L.; Cherif, M.; Boudechiche, L.; Sammar, F. Teneurs en composés primaires et secondaires des feuilles d'arbustes fourragers de la région humide d'Algérie. Rev. Med. Vet. 2014, 165, 344-352.

19. Bhatt, R.S.; Soren, M.N.; Sahoo, A.; Karim, S.A. Level and period of realimentation to assess improvement in body condition and carcass quality in cull ewes. Trop. Anim. Health Prod. 2013, 45, 167-176. [CrossRef]

20. Ha, J.K.; Lindsay, R.C. Distribution of volatile-branched chain fatty acids in perinephric fats of various red meat species. LWT 1990, 23, 433-440.

21. Yagoubi, Y.; Hajji, H.; Smeti, S.; Mahouachi, M.; Kamoun, M.; Atti, N. Growth performance, carcass and non-carcass traits and meat quality of Barbarine lambs fed rosemary distillation residues. Animal Int. J. Anim. Biosci. 2018, 12, 2407-2414. [CrossRef] [PubMed]

22. Ahn, J.; Grun, I.U.; Fernando, L.N. Antioxidant properties of natural plant extracts containing polyphenolic compounds in cooked ground beef. J. Food Sci. 2002, 67, 1364-1369. [CrossRef]

23. Atti, N.; Mahouachi, M. The effects of diet, slaughter weight, and docking on growth, carcass composition and meat quality of fat-tailed Barbarine lambs: A review. Trop. Anim. Health Prod. 2011, 43, 1371-1378. [CrossRef] [PubMed] 
24. Gallardo, B.; Manca, M.G.; Mantecón, A.R.; Nudda, A.; Manso, T. Effects of linseed oil and natural or synthetic vitamin E supplementation in lactating ewes' diets on meat fatty acid profile and lipid oxidation from their milk fed lambs. Meat Sci. 2015, 102, 79-89. [CrossRef]

25. López-Bote, C.J.; Daza, A.; Soares, M.; Berges, E. Dose-response effect of dietary vitamin E concentration on meat quality characteristics in light-weight lambs. J. Anim. Sci. 2001, 73, 451-457. [CrossRef]

26. Gómez-Cortés, P.; Guerra-Rivas, C.; Gallardo, B.; Lavín, P.; Mantecón, A.R.; De la Fuente, M.A.; Manso, T. Grape pomace in ewe's diet: Effects on meat quality and the fatty acid profile of their suckling lambs. Food Res. Int. 2018, 113, 36-42. [CrossRef]

27. Ripoll, G.; González-Calvo, L.; Molino, F.; Calvo, J.H.; Joy, M. Effects of finishing period length with vitamin E supplementation and alfalfa grazing on carcass color and the evolution of meat color and the lipid oxidation of light lambs. Meat Sci. 2013, 93, 906-913. [CrossRef]

28. Lobón, S.; Sanz, A.; Blanco, M.; Ripoll, G.; Joy, M. The type of forage and condensed tannins in dams' diet: Influence on meat shelf life of their suckling lambs. Small Rumin. Res. 2017, 154, 115-122. [CrossRef]

29. Frankel, E.N.; Huang, S.W.; Aeschbach, R.; Prior, E. Antioxidant activity of a rosemary extract and its constituents, carnosic acid, carnosol, and rosmarinic acid, in bulk oil and oil-in-water emulsion. J. Agric. Food Chem. 1996, 44, 131-135. [CrossRef]

30. Bañón, S.; Méndez, L.; Almela, E. Effects of dietary rosemary extract on lamb spoilage under retail display conditions. Meat Sci. 2012, 90, 579-583. [CrossRef]

31. Escalante, A.S.; Dienane, D.; Torrescano, G.; Beltran, J.A.; Roncales, P. The effects of ascorbic acid, taurine, carnosine and rosemary powder on colour and lipid stability of beef patties packaged in modified atmosphere. Meat Sci. 2001, 58, 421-429. [CrossRef]

32. Kerry, J.P.; Buckley, D.J.; Morrisey, A.; O’Sullivan, K.; Lynch, P.B. Endogenous and exogenous a-tocopherol supplementation: Effects on lipid stability (TBARS) and warmed-over flavour (WOF) in porcine $\mathrm{M}$. longissimus dorsi roasts held in aerobic and vacuum packs. Food Res. Int. 1999, 31, 211-216. [CrossRef]

33. Vasta, V.; Luciano, G. The effects of dietary consumption of plants secondary compounds on small ruminants' products quality. Small Rumin. Res. 2011, 101, 150-159. [CrossRef]

34. MacDougall, D.B. Changes in the color and opacity of meat. Food Chem. 1982, 9, 75-88. [CrossRef]

35. Cheah, K.S.; Chreah, A.M.; Krausgrill, D.J. Effect of dietary supplementary vitamin E on pig meat quality. Meat Sci. 1995, 39, 255-265. [CrossRef]

36. Realini, C.E.; Duckett, S.K.; Brito, G.W.; Dalla Rizza, M.; De Mattos, D. Effect of pasture vs. concentrate feeding with or without antioxidants on carcass characteristics, fatty acid composition, and quality of Uruguayan beef. Meat Sci. 2004, 66, 567-577. [CrossRef]

37. Santé-L'houtellier, V.; Engel, E.; Gatellier, P.H. Assessment of the influence of diet on lamb meat oxidation. Food Chem. 2008, 109, 573-579. [CrossRef]

38. Chan, D.E.; Walker, P.N.; Mills, E.W. Prediction of pork quality characteristics using visible and near-infrared spectroscopy. Trans. ASAE 2002, 45, 1519-1527.

39. Andrés, S.; Morán, L.; Aldai, N.; Tejido, M.L.; Prieto, N.; Bodas, R.; Giráldez, F.J. Effects of linseed and quercetin added to the diet of fattening lambs on the fatty acid profile and lipid antioxidant status of meat samples. Meat Sci. 2014, 97, 156-163. [CrossRef]

40. Vasta, V.; Pennisi, P.; Lanza, M.; Barbagallo, D.; Bella, M.; Priolo, A. Intramuscular fatty acid composition of lambs given a tanniniferous diet with or without polyethylene glycol supplementation. Meat Sci. 2007, 76, 739-745. [CrossRef]

41. Young, O.A.; Lane, G.A.; Podmore, C.; Fraser, K.; Agnew, M.J.; Cummings, T.L.; Cox, N.R. Changes in composition and quality characteristics of ovine meat and fat from castrates and rams aged to 2 years. N. Z. J. Agric. Res. 2006, 49, 419-430. [CrossRef]

42. Wong, E.; Nixon, L.N.; Johnson, C.B. Volatile medium chain fatty acids and mutton flavor. J. Agric. Food Chem. 1975, 23, 495-498. [CrossRef]

43. EFSA. Panel on Dietetic Products, Nutrition, and Allergies (NDA). Scientific Opinion on Dietary Reference Values for fats, including saturated fatty acids, polyunsaturated fatty acids, monounsaturated fatty acids, trans fatty acids, and cholesterol. EFSA 2010, 8, 1461.

44. Raes, K.; De Smet, S.; Demeyer, D. Effect of dietary fatty acids on incorporation of long chain polyunsaturated fatty acids and conjugated linoleic acid in lamb, beef and pork meat: A review. Anim. Feed Sci. Technol. 2004, 113, 199-221. [CrossRef] 
45. Resconi, V.C.; Pascual-Alonso, M.; Aguayo-Ulloa, L.; Miranda-De La Lama, G.C.; Alierta, S.; Campo, M.M.; María, G.A. Effect of Dietary Grape Pomace and Seed on Ewe Milk and Meat Quality of Their Suckling Lambs. J. Food Qual. 2018, 5, 1-8. [CrossRef]

46. Enser, M.; Scollan, N.; Gulati, S.; Richardson, I.; Nute, G.; Wood, J. The effects of ruminally-protected dietary lipid on the lipid composition and quality of beef muscle. In Proceedings of the 47th International Congress of Meat Science and Technology, Kraków, Poland, 26-31 August 2001; Volume 1, pp. 12-13.

47. Guerrero, A.; Sañudo, C.; Campo, M.M.; Olleta, J.L.; Muela, E.; Macedo, R.M.G.; Macedo, F.A.F. Effect of linseed supplementation level and feeding duration on performance, carcass and meat quality of cull ewes. Small Rumin. Res. 2018, 167, 70-77. [CrossRef]

48. Gray, J.I.; Gomaa, E.A.; Buckley, D.J. Oxidative quality and shelf life of meats. Meat Sci. 1996, 43, 111-123. [CrossRef]

49. Morrissey, P.A.; Sheehy, P.J.A.; Galvin, K.; Kerry, J.P.; Buckley, D.J. Lipid stability in meat and meat products. Meat Sci. 1998, 49, 73-86. [CrossRef]

50. Nieto, G.; Ros, G. Modification of fatty acid composition in meat through diet: Effect on lipid peroxidation and relationship to nutritional quality, a review. Lipid Peroxidation 2012, 12, 239-258.

51. Recsan, Z.; Pagliuca, G.; Piretti, M.V.; Penzes, L.G.; Youdim, K.A.; Noble, R.C.; Deans, S.G. Effect of essential oils on the lipids of the retina in the ageing rat: A possible therapeutic use. J. Essent. Oil Res. 1997, 9, 53-56. [CrossRef]

52. Pogorzelska, E.; Godziszewska, J.; Brodowska, M.; Wierzbicka, A. Antioxidant potential of Haematococcus pluvialis extract rich in astaxanthin on colour and oxidative stability of raw ground pork meat during refrigerated storage. Meat Sci. 2018, 135, 54-61. [CrossRef] [PubMed]

53. AOAC. Association of Official Analytical Chemists. In Official Methods of Analysis, 15th ed.; AOAC: Arlington, VA, USA, 1999.

54. Botsoglou, N.A.; Fletouris, D.J.; Papageorgiou, G.E.; Vassilopoulos, V.N.; Mantis, A.J.; Trakatellis, A.G. Rapid, sensitive, and specific thiobarbituric acid method for measuring lipid peroxidation in animal tissue, food, and feedstuff samples. J. Agric. Food Chem. 1994, 42, 1931-1937. [CrossRef]

55. Vázquez, C.V.; Rojas, M.V.; Ramírez, C.A.; Chávez-Servín, J.L.; García-Gasca, T.; Martínez, R.A.F.; Montemayor, H.M.A. Total phenolic compounds in milk from different species. Design of an extraction technique for quantification using the Folin-Ciocalteu method. Food Chem. 2015, 176, 480-486. [CrossRef] [PubMed]

56. Saura-Calixto, F.; Goñi, I. Antioxidant capacity of the Spanish Mediterranean diet. Food Chem. 2006, 94, 442-447. [CrossRef]

57. Prates, J.A.M.; Quaresma, M.A.G.; Bessa, R.J.B.; Fontes, C.M.A.; Alfaia, C.M.M. Simultaneous HPLC quantification of total cholesterol, tocopherols and $\beta$-carotene in Barrosã-PDO veal. Food Chem. 2006, 94, 469-477. [CrossRef]

58. Tibaoui, S.; Essid, I.; Smeti, S.; Bertolin, J.R.; Joy, M.; Atti, N. Fatty acid profile, physiochemical properties and oxidative stability of ewe's sausage as affected by distillated myrtle (Myrtuscommunis) leaves' intake. Int. J. Food Sci. 2020, 55, 1151-1161. [CrossRef]

59. Lee, M.R.F.; Tweed, J.K.S.; Kim, E.J.; Scollan, N.D. Beef, chicken and lamb fatty acid analysis-A simplified direct bimethylation procedure using freeze-dried material. Meat Sci. 2012, 92, 863-866. [CrossRef]

60. Ulbricht, T.L.; Southgate, D.A.T. Coronary heart disease: Seven dietary factors. The Lancet 1991, 338, $985-992$. [CrossRef]

Sample Availability: Samples of the compounds are available from the authors. 